\title{
Original
}

\section{Calcification of Pulp Canal Space after Replantation of Immature Rat Molars}

\author{
Ikuo Ihara'), Yasuo Miake'), Kazuki Morinaga' ${ }^{1)}$, Takaaki Yatsuhashi' ${ }^{1)}$ \\ Kan-Ichi Nakagawa ${ }^{1)}$ and Takaaki Yanagisawa ${ }^{2)}$

\begin{abstract}
${ }^{1)}$ Department of Endodontics, Pulp and Periapical Biology, Tokyo Dental College, 1-2-2 Masago, Mihama-ku, Chiba
${ }^{2)}$ Department of Ultrastructural Science ${ }^{2)}$, Tokyo Dental College,1-2-2 Masago, Mihama-ku, Chiba

(Accepted for publication, April 27, 2007)
\end{abstract}

\begin{abstract}
The objective of this study was to investigate the process of hard tissue formation after replantation of open-ended immature teeth in rat and morphologically type the hard tissue generated according to its degree of calcification. The pulp chamber, periapical cells and matrix were observed by light microscopy. Degree of ossification in undecalcified, polished samples was determined by contact microradiography (CMR). After tooth replantation, pulp cells and odontoblasts temporarily showed degeneration and necrosis. Thereafter, some of the surviving pulp cells showed activation, with healing and revascularization of apical tissue, proliferating to form matrix. These results together with the CMR findings showed that bone-like dentin was formed in the cervical pulp chamber, and that intracanal cementogenesis occurred in the apical area, continuing until the pulp chamber was filled with calcified tissues.
\end{abstract}

Key words : Open-ended immature teeth, Replantation, Contact microradiography

\section{Introduction}

Tooth luxation has been reported to induce various reactions in hard and soft tissues ${ }^{1-7)}$. When vital teeth with open-ended immature roots are extracted and replanted, calcification in the pulp chamber increases with time. Luxation of teeth leads to obliteration of the pulp canal space, depending on the severity of the injury to the pulp.

This functional recovery has been reported to be accompanied by deposition of hard tissue in the root canal and pulp chamber ${ }^{8-}$ ${ }^{11)}$. A number of studies have found that pulp regeneration and pulp chamber calcification occurred with no pulp necrosis or apical periodontitis in patients followed up over a long period after dental trauma ${ }^{12-20)}$. However, these reports concerned diagnoses based on changes in tooth color and pulp vitality or radiography.

The aim of this study was to investigate the process of hard tissue formation after replantation of teeth with open-ended immature roots in rat and morphologically type the hard tissue generated according to its degree of calcification.

\section{Materials and Methods}

The maxillary right first molars of twenty-seven 4-week-old male Wistar rats weighing approximately $100 \mathrm{~g}$ each were used

Correspondence to : Ikuo Ihara Department of Endodontics, Pulp and Periapical Biology ${ }^{1)}$, Department of Ultrastructural Science ${ }^{2)}$, Tokyo Dental College, 1-2-2 Masago, Mihama-ku, Chiba Tel: 043-270-3950 Fax: 043-270-3951 in this study. After the animals were anesthetized by diethyl ether inhalation, general anesthesia was induced by an injection of ketamine hydrochloride (Ketaral injection, Dainippon Pharmaceutical Co., Ltd.) at a weight-adjusted dose $(0.3 \mathrm{ml} / 100$ g). The teeth were luxated with a dental excavator and extracted using forceps, taking care not to damage the periodontal tissue. They were then immediately replanted while taking into account preoperative occlusion. Replantation was performed with no washing of the sockets. The maxillary left first molars were used as controls. The evaluation periods were 7,14 , and 28 days, during which time the animals were fed a powdered diet (Oriental Yeast Co.). The animals were cared for and treated throughout the study according to the Guidelines for Handling of Experimental Animals of Tokyo Dental College.

After each evaluation period, the animals were given general anesthesia via intraperitoneal administration of ketamine hydrochloride and fixed by perfusion with a $4 \%$ paraformaldehyde- $2.5 \%$ glutaraldehyde fixative solution for about 20 minutes. Upper molars were extracted together with the alveolar bones, which were then fixed in the same fixative solution for approximate 12 hours. The specimens were then washed in buffer, and some were decalcified for light microscopy with 10\% EDTA solution $\left(\mathrm{pH} \mathrm{7.3)}\right.$ ) for about 6 weeks at $4^{\circ} \mathrm{C}$ and dehydrated in a graded alcohol series. 
Ikuo Ihara et al.: Calcification of pulp canal space after replantation of immature rat molars

\section{Light microscopy}

The dehydrated samples were cleared with xylene and embedded in paraffin. Sections $6 \mathrm{~mm}$ in thickness extending to the mesial apex along the dental axis were prepared. After hematoxylin-eosin staining (H-E staining), the samples were examined under a light microscope (ECLIPSE E600, Nikon, Tokyo). The apical area and cervical pulp chamber of the mesial root were selected as sites for examination.

\section{Contact microradiography}

After fixation, undecalcified samples were dehydrated and embedded in polyester resin (Rigolac, Nisshin EM, Tokyo). Samples $100 \mathrm{~mm}$ in thickness were prepared after longitudinal polishing through the center of the mesial root. Contact microradiography (CMR) was performed with a soft X-ray generator (CMR-3, Softex, Tokyo) at $10 \mathrm{kV}, 3 \mathrm{~mA}$ (sample-focus distance $44.4 \mathrm{~mm}$, exposure time $10 \mathrm{~min}$ ). An aluminum step wedge was incorporated in each CMR image. The films used were High Precision Photo Plates (HRP-SN-2, Konica Minolta, Tokyo).

The CMR images obtained were examined microscopically and inputted via a digital camera into an image analyzer (HC-2500, Olympus, Tokyo). The degree of calcification (Vol\%) was evaluated according to the image density of the aluminum step wedge. The evaluation sites were the area of hard tissue formation in the apical area and cervical pulp chamber of the mesial root in the experimental groups, and the dentin, cementum and bone in the mesial area of the mesial root in the control groups. Dentin was examined at the center of its thickness at a point near the cervix, cementum at the center of its thickest point and alveolar bone along the horizontal extension from the examination site of the cementum. Multiple comparisons using Tukey's test (SAS Ver.9.1) were performed for statistical analysis.

\section{Results}

\section{Light microscopy (H-E stain)}

\section{1) Control groups}

High columnar odontoblasts were revealed in the apical area, as well as on the cervical pulp wall, and dentinogenesis was observed. Cementogenesis was observed around the apex (Figs. 1 and 2). At 7 days, the roots were still immature, and wide apical foramina were observed (Fig. 1). At 28 days, formation of apical foramina and thickening of surrounding cellular cementum associated with root growth were observed (Fig. 2).

\section{2) Experimental groups}

\section{(1) 7 days after replantation}

In the cervical pulp chamber, the odontoblast layer disappeared, and fibroblast-like cells with irregular contours were observed along the pulp wall. The cells were more numerous than in the center of the pulp and were piled up in 2-3 layers. Predentin partially remained (Fig. 3a, b).

No odontoblasts were noted near the apical foramen, and an irregular matrix in which many cells were embedded was formed, continuous with the surrounding cellular cementum. Root formation was arrested, and the apical foramina were being closed by the irregular matrix. Some of the cementum around the roots was resorbed, and round cell infiltration was noted (Fig. 3a,c).

\section{(2) 14 days after replantation}

In the cervical pulp chamber, predentin and the odontoblast layers disappeared, and the formation of irregular matrix continuous with dentin was noted. Many cells surrounded by wide spaces were embedded in the matrix. Cuboid or flat cells were observed on the pulp side of this matrix (Fig. 4a, b).

The amount of irregular matrix near the root apex showed an increase in comparison with that in the samples examined after 7 days. Both the volume and number of cells embedded in the matrix were reduced. The apical foramina were surrounded by irregular matrix and were closed. Some of the cementum around the root was resorbed or showed dental ankylosis, and round cells infiltrating the area around the cementum were disappearing (Fig. $4 \mathrm{a}, \mathrm{c})$.

\section{(3) 28 days after replantation}

The formation of irregular matrix continuous with dentin was observed in the cervical pulp chamber. Fewer cells were embedded in the matrix than at after 14 days, and the spaces around the cells were reduced. High odontoblast-like cells were arranged in an irregular single layer on the pulp side of the matrix. A predentinlike structure was noted in a narrow area (Fig. 5a, b).

The amount of irregular matrix near the apical foramen showed no change compared with at 14 days after replantation. Cells embedded in the matrix disappeared, and the spaces around them were reduced. Cuboid or flat cells around the matrix resembled cementoblasts or fibroblasts. Similar to the samples examined after 14 days, the cementum around the root was partly resorbed or showed dental ankylosis (Fig. 5a, c).

\section{CMR images \\ 1) Control groups}

Calcified tissues, i.e., dentin, cementum and alveolar bone, were clearly observed, but no calcified tissue was noted in the pulp chamber or apical foramen (Figs. 6 and 7). In the samples examined after 7 days, the roots were immature, wide apical foramina were observed, and the amount of cementum was small (Fig. 6). In those examined after 28 days, however, the roots were mature, and the amount of cementum was increased (Fig. 7).

\section{2) Experimental groups}

\section{(1) 7 days after replantation}

No change was noted in degree of calcification in the cervical 


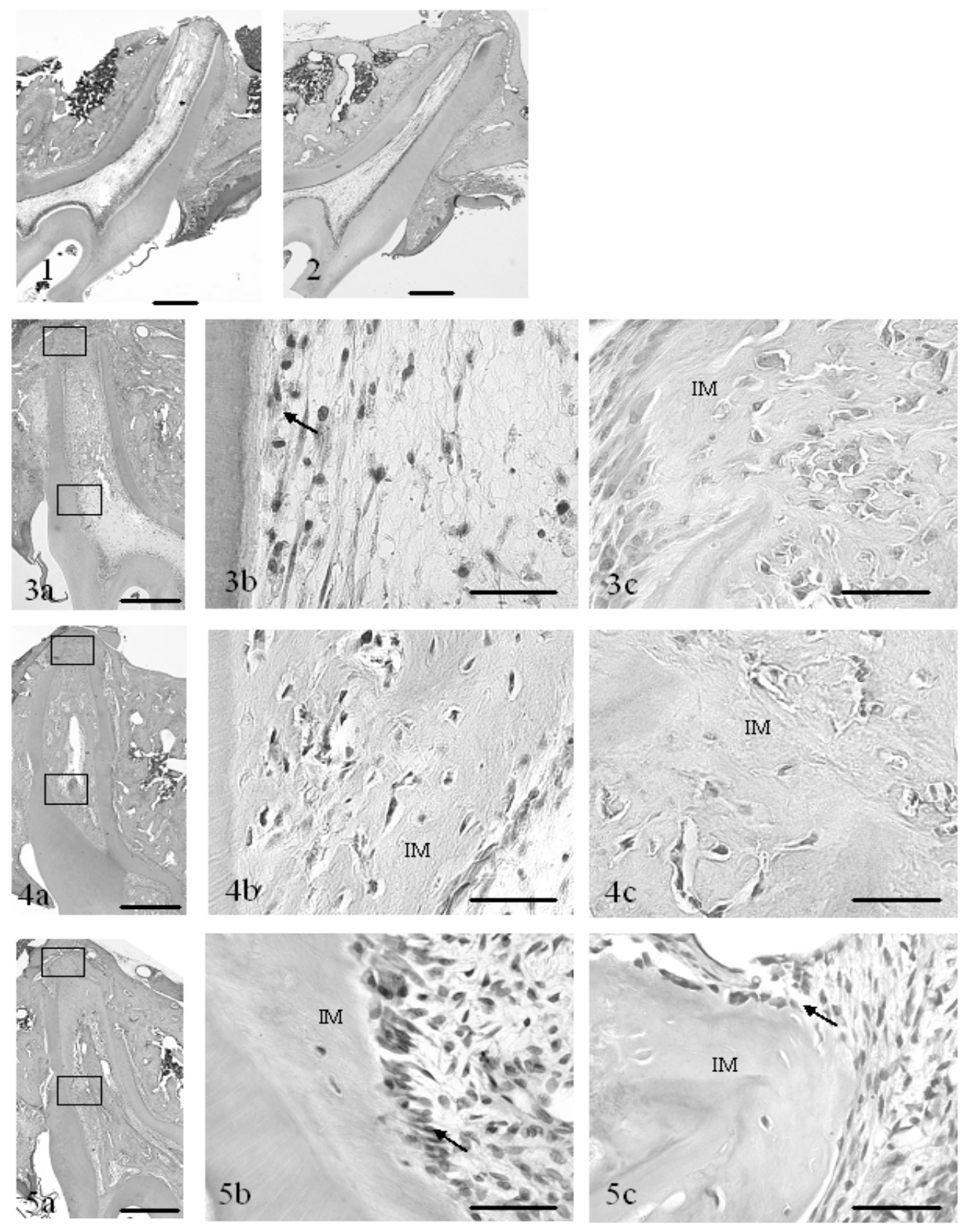

Fig. 1: Control after 7 days. (bar $=500 \mu \mathrm{m}$ H-E staining)

Fig. 2: Control after 28 days. (bar $=500 \mu \mathrm{m} \mathrm{H-E} \mathrm{staining)}$

Fig. 3 a: 7 days after replantation. Irregular matrix formation noted in apical area. (bar $=500 \mu \mathrm{m}$ H-E staining)

b: 7 days after replantation. Cervical pulp chamber. Fibroblast-like cells (arrow) on root canal wall. ( $b a r=100 \mu \mathrm{m} \mathrm{H-E}$ staining)

c: 7 days after replantation. Apical area. Formation of irregular matrix (IM) with embedded cells. (bar $=100 \mu \mathrm{m} \mathrm{H-E} \mathrm{staining)}$

Fig. 4 a: 14 days after replantation. Irregular matrix (IM) formed throughout entire pulp chamber, extending to area around apical area and obstructing apical foramen. (bar $=500 \mu \mathrm{m} \mathrm{H-E} \mathrm{staining)}$

b: 14 days after replantation. Cervical pulp chamber. Formation of irregular matrix (IM) continuous with dentin. $\quad($ bar $=100 \mu \mathrm{m}$ H-E staining)

c: 14 days after replantation. Apical area. Irregular matrix (IM) obstructing apical foramina. (bar $=100 \mu \mathrm{m} \mathrm{H-E} \mathrm{staining)}$

Fig. 5 a: 28 days after replantation. Increased hard tissue filling most of pulp chamber. Apical foramen closed by matrix. (bar $=500$ $\mu \mathrm{m}$ H-E staining)

b: Sample 28 days after replantation. Cervical pulp chamber. Odontoblast-like cells (arrow) along irregular matrix (IM). (bar $=100 \mu \mathrm{m}$ H-E staining)

c: Sample 28 days after replantation. Apical area. Cementoblast- and fibroblast-like cells (arrow) around matrix (IM). (bar= $100 \mu \mathrm{m}$ H-E staining) 

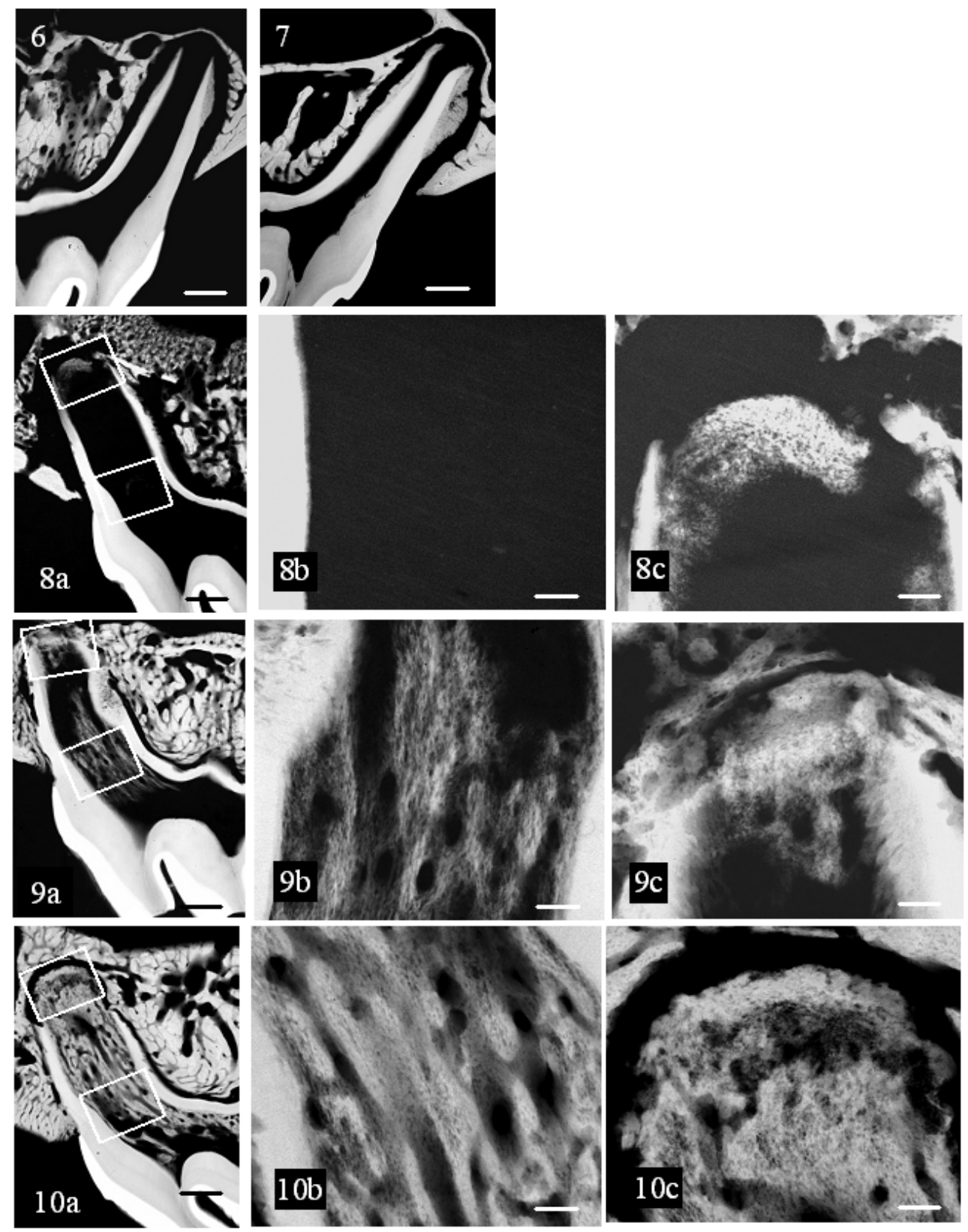

Fig. 6: Control after 7 days. Hard tissues, i.e., dentin, cementum and bone. (bar $=500 \mu \mathrm{m} \mathrm{CMR)}$

Fig. 7: Control after 28 days. Increases in thickness of dentin and cementum, growth of root and formation of root foramen noted. (bar $=500 \mu \mathrm{m} \mathrm{CMR})$

Fig. 8 a: 7 days after replantation. Apical area, calcified tissues formed and periodontal space widened. $($ bar $=500 \mu \mathrm{m} \mathrm{CMR})$ b: 7 days after replantation. Cervical pulp chamber. No calcified tissue formed. (bar $=100 \mu \mathrm{m} \mathrm{CMR)}$

c: 7 days after replantation. Apical area. Calcified tissues formed in areas corresponding to matrix. $(\mathrm{bar}=100 \mu \mathrm{m} C M R)$

Fig. 9 a: 14 days after replantation. Calcified tissues are formed in the cervical pulp chamber and apical area. (bar $=500 \mu \mathrm{m} \mathrm{CMR)}$ b: 14 days after replantation. Cervical pulp chamber. Hard tissue with a low degree of calcification is formed in areas corresponding to the matrix. (bar $=100 \mu \mathrm{m} \mathrm{CMR)}$

c: 14 days after replantation. Apical area. Amount of hard tissue and degree of its ossification increased. $($ bar $=100 \mu \mathrm{m}$ CMR)

Fig. 10 a: 28 days after replantation. Calcified tissues in cervical pulp chamber are continuous with those in apical area and filling most of the pulp chamber. (bar $=500 \mu \mathrm{m} \mathrm{CMR)}$

b: 28 days after replantation. Cervical $\mu$ pulp chamber. Amount of hard tissue in cervical pulp chamber and degree of its calcification increased. $(\mathrm{bar}=100 \mu \mathrm{m} \mathrm{CMR})$

c: 28 days after replantation. Apical area. No change observed in degree of calcification in hard apical tissue. $($ bar $=100$ $\mu \mathrm{m}$ CMR) 


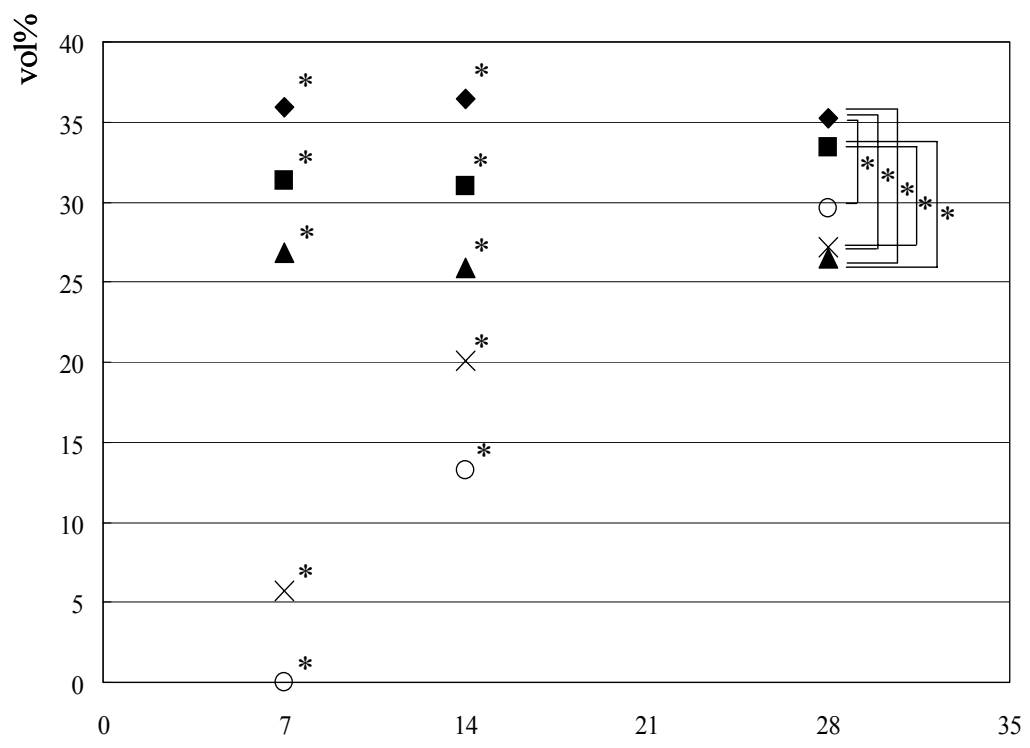

Fig.11. Changes in mineral contents. Significant differences seen in degree of calcification of all hard tissue in 7-and 14-day specimens. $(\mathrm{p}<0.0001),{ }^{*}$ significant differences. $(\mathrm{p}<0.0001)(\mathrm{n}=6) \diamond$ Dentin $\boldsymbol{\square}$ Bone $\boldsymbol{\Delta}$ Cementium $\times$ Calcified tissue in apical area $\bullet$ Calcified tissue in cervical pulp chamber

pulp chamber, similar to in the control group (Fig. 8a, b). In the apical area, however, formation of hard tissue with a low degree of calcification was noted in the area corresponding to the matrix observed in the H-E-stained samples. In some of the dental roots, resorption of dentin or cementum was noted, alveolar bone around the root was markedly resorbed, and the periodontal space was enlarged (Fig. 8a, c).

\section{(2) 14 days after replantation}

In the cervical pulp chamber, formation of hard tissue with a low degree of calcification was noted in the area corresponding to the matrix observed in the H-E-stained samples. The calcified tissue was elongated along the dental axis and showed cavities of various sizes inside (Fig. 9a, b). In the apical area, the amount of hard tissue and degree of calcification were increased, and the apical foramina appeared to be closed. Root dentin and cementum were markedly resorbed in some places, but cementum showed an increase and adhered to bone in other areas (Fig. 9a, c).

\section{(3) 28 days after replantation}

Calcified materials in the cervical pulp chamber showed a further increase, filling most of the pulp chamber in some samples.
The degree of ossification was greater than that at 14 days after surgery, and many cavities of different sizes were observed in calcified areas (Fig. 10a, b). Although hard apical tissue showed no change in degree of calcification, its amount showed an increase, and was continuous with hard tissue growing from inside the cervical pulp chamber (Fig. 10a, c).

\section{Mineral content}

Mineral content was determined in the cementum, dentin and bone of the control group and hard tissue formed in the apical area and pulp chamber of the experimental groups (Table 1).

Little change in degree of calcification with time was noted in dentin or cementum in the control group. In bone, however, degree of calcification showed a slight increase at 28 days.

In the experimental groups, degree of calcification of hard tissue formed in the pulp chamber was low at after 14 days, but increased rapidly thereafter, and was lower than that of bone at after 28 days. There was no significant difference between them $(\mathrm{p}<0.001)$. The degree of calcification of hard tissue formed in the apical area was very low at 7 days, but then increased progressively, becoming comparable to that of cementum in the control group

Table 1: Mineral contents. (same as previous text)

\begin{tabular}{cllccc}
\hline & Dentin & Bone & Cementium & $\begin{array}{c}\text { Calcified tissue } \\
\text { apical area }\end{array}$ & $\begin{array}{c}\text { Calcified tissue in } \\
\text { cervical pulp chanber }\end{array}$ \\
\hline 7 days & 35.94 & 31.37 & 26.85 & 5.75 & 0 \\
& $( \pm 1.38)$ & $( \pm 2.15)$ & $( \pm 1.57)$ & $( \pm 3.56)$ & 0 \\
14 days & 36.45 & 30.97 & 25.91 & 20.07 & 13.24 \\
& $( \pm 0.57)$ & $( \pm 2.40)$ & $( \pm 2.65)$ & $( \pm 3.34)$ & $( \pm 2.46)$ \\
28 days & 35.28 & 33.45 & 26.52 & 27.18 & 29.6 \\
& $( \pm 1.66)$ & $( \pm 3.09)$ & $( \pm 2.97)$ & $( \pm 1.56)$ & $( \pm 1.09)$ \\
\hline
\end{tabular}


Ikuo Ihara et al.: Calcification of pulp canal space after replantation of immature rat molars

after 28 days $(\mathrm{p}<0.001)$. Furthermore, the degree of calcification of all hard apical tissue was lower than that of dentin or bone $(\mathrm{p}<0.001)$ (Fig. 11).

\section{Discussion}

\section{Pulp regeneration}

There have been a number of studies on the regeneration of damaged human dental pulp ${ }^{12-20)}$. Ritter et al. found that pulp blood vessels showed regeneration in $33 \%$ of immature canine teeth after replantation ${ }^{8}$. Skoglund et al. reported infiltration of newly-formed vessels into pulp immediately after surgery, in half of the roots after 10 days and in the entire pulp after 30 days ${ }^{10)}$.

In this study, pulp regeneration was observed immediately after replantation, although the recovery process differed markedly among cell types. At 7 days, odontoblasts responded sensitively to arrested blood supply due to vascular disruption, and many of them necrosed and disappeared. Odontoblasts are highly differentiated cells that produce a large amount of protein (collagen fibers) and, for this purpose, continuously require large amounts of oxygen and nutrients. Revascularization was delayed in the cervical pulp chamber compared with in the apical area, and necrosis was more notable. Predentin was observed in the H-Estained samples in this area, suggesting it was a remnant of the original predentin. Cells observed in this region are believed to have been proper pulp cells (fibroblasts) that survived, proliferated with revascularization and adhered. Thereafter, fibroblasts in the pulp chamber differentiated and proliferated with vascular regeneration, commencing to produce a large amount of matrix in the cervical area. At 28 days, differentiation of cells morphologically considered to be odontoblasts was observed. No dentinal tubules were noted in the matrix in contact with odontoblasts. In the cervical pulp, matrix restoration to a level comparable with that in the original dentin was considered to have been impossible during the observation period due to the delay in revascularization.

In the apical area, however, blood supply was quickly restored after replantation, and many cells already showed proliferation at 7 days after surgery, forming an irregular matrix. After 28 days, a large amount of matrix with cells embedded in it was observed, suggesting cellular cementogenesis in the apical area.

\section{Calcified tissue in pulp chamber}

Calcified tissues form in the pulp chamber with degeneration or necrosis of the pulp ${ }^{21)}$. However, the calcified tissues observed in the pulp chamber in this study differed from petrifaction deposits. No calcified tissue was noted in the necrotic tissue in the cervical pulp chamber, and it was first detected by radiography after cell proliferation and the formation of osteoid matrix. These findings suggest that these calcified tissues were formed under cell control, rather than by the passive deposition of calcium salts. The degree of calcification increased rapidly in the calcified tissues in the cervical pulp chamber, although it was still lower than that of bone after 28 days. Although observation was ended after 28 days, the degree of calcification at this site may have approached that of dentin if the observation had been continued. The changes in cell morphology and degree of matrix calcification suggest the eventual formation of tubular dentin. In the apical area, however, the formation of calcified tissues was already noted at 7 days after replantation. Many cells and matrices were formed at this site, similarly to in the pulp chamber. At 28 days, the degree of calcification suggested that the tissue formed was similar to cementum.

Robertson et al. reported that tissues that block the pulp chamber exhibit reparative reactions by dentin-like, bone-like, or fibrous tissues $^{22)}$. They also reported pulp necrosis due to root canal obstruction after trauma in $8.5 \%$ of teeth, noting that this percentage increased with time ${ }^{23)}$. In this study, however, the calcified tissue formed in the pulp chamber was bone-like dentin, whereas that formed in the apical area was considered to be cementum. According to Robertson et al., root canal obliteration after trauma was notable in immature teeth, with subsequent pulp necrosis due to rapid obliteration of the entire root canal ${ }^{23)}$. In our study, no pulp necrosis due to root canal obliteration was noted. However, the possibility that pulp necrosis might have occurred if the study had been continued until complete obliteration of the root canal by increasing cementum in the apical area cannot be excluded.

Therefore, in the clinical treatment of dental injury, although restoration of the original pulp structure is desirable in immature teeth, the results of this study suggest that calcified tissues forming in the pulp prevent subsequent root formation. A simple comparison between rats and humans is impossible due to wide biological differences. Therefore, the underlying mechanism of changes in replanted rat teeth will require further clarification in obtaining more accurate diagnoses and effective treatment for damaged human teeth.

\section{Conclusion}

The results of this study suggest that pulp cells and odontoblasts become hypoxic after replantation due to temporary suspension of blood flow, with subsequent degeneration and necrosis of proper pulp cells and odontoblasts. Some surviving pulp cells activated by healing and revascularization of apical tissue form a matrix and subsequently differentiate. As a result, bone-like dentin is formed in the cervical pulp chamber, cementogenesis in the root canal begins from the apical area and the pulp cavity is filled with calcified tissues. These changes, if allowed to continue, may eventually induce pulp necrosis.

\section{Acknowledgement}

We would like to thank Associate Professor Jeremy Williams 59 


\section{References}

1. Robertson A. Pulp survival and hard tissue formation subsequent to dental trauma. A clinical and histological study of uncomplicated crown fractures and luxation injuries. Swed Dent J Suppl 125: 1-65, 1997

2. Crona-Larsson G, Bjarnason S and Noren JG. Effect of luxation injuries on permanent teeth. Endod Dent Traumatol 7(5): 199206, 1991

3. Miyashin M, Kato J and Takagi Y. Tissue reactions after experimental luxation injuries in immature rat teeth. Endod Dent Traumatol 7(1): 26-35, 1991

4. Dumsha T and Hovland EJ. Pulpal prognosis following extrusive luxation injuries in permanent teeth with closed apexes. J Endod 8(9): 410-2, 1982

5. Jacobsen I. Criteria for diagnosis of pulp necrosis in traumatized permanent incisors. Scand J Dent Res 88(4): 306-12, 1980

6. Andreasen JO. Luxation of permanent teeth due to trauma. A clinical and radiographic follow-up study of 189 injured teeth. Scand J Dent Res. 1970;78(3):273-86.

7. Birkedal-Hansen $H$. External root resorption caused by luxation of rat molars. Scand J Dent Res.81(1): 47-61, 1973

8. Ritter AL, Ritter AV, Murrah V, Sigurdsson A and Trope M. Pulp revascularization of replanted immature dog teeth after treatment with minocycline and doxycycline assessed by laser Doppler flowmetry, radiography, and histology. Dent Traumatol 20(2):75-84, 2004

9. Cohenca N, Karni S and Rotstein I. Transient apical breakdown following tooth luxation. Dent Traumatol 19(5): 289-91, 2003

10. Skoglund A, Tronstad L and Wallenius K. A microangiographic study of vascular changes in replanted and autotransplanted teeth of young dogs. Oral Surg Oral Med Oral Pathol 45(1):1728, 1978

11. Diab $M$ and elBadrawy HE. Intrusion injuries of primary incisors. Part II: Sequelae affecting the intruded primary incisors. Quintessence Int 31(5): 335-41, 2000

12. Andreasen JO, Borum MK, Jacobsen HL and Andreasen FM. Replantation of 400 avulsed permanent incisors. 1. Diagnosis of healing complications. Endod Dent Traumatol 11(2): 518,1995
13. Andreasen JO, Borum MK, Jacobsen HL and Andreasen FM. Replantation of 400 avulsed permanent incisors. 2. Factors related to pulpal healing. Endod Dent Traumatol 11(2):5968,1995

14. Andreasen JO, Borum MK and Andreasen FM. Replantation of 400 avulsed permanent incisors. 3. Factors related to root growth. Endod Dent Traumatol 11(2): 69-75, 1995

15. Andreasen JO, Borum MK, Jacobsen HL and Andreasen FM. Replantation of 400 avulsed permanent incisors. 4. Factors related to periodontal ligament healing. Endod Dent Traumatol 11(2): 76-89, 1995

16. Andreasen FM, Zhijie Y, Thomsen BL and Andersen PK. Occurrence of pulp canal obliteration after luxation injuries in the permanent dentition. Endod Dent Traumatol 3(3): 10315, 1987

17. Cleen. M. Obliteration of pulp canal space after concussion and subluxation: endodontic considerations. Quintessence Int 33(9): 661-9, 2002

18. Boyd KS. Transient apical breakdown following subluxation injury: a case report. Endod Dent Traumatol 11(1): 37-40, 1995

19. Andreasen FM. Transient apical breakdown and its relation to color and sensibility changes after luxation injuries to teeth. Endod Dent Traumatol 2(1): 9-19, 1986

20. Jacobsen I and Sangnes G. Traumatized primary anterior teeth. Prognosis related to calcific reactions in the pulp cavity. Acta Odontol Scand 36(4): 199-204, 1978

21. Cohen S and Burns RC. Path ways of the PULP EIGHTH EDITION, ed. by Cohen S, Burns RC, Inc., Mosby, 2002, pp 603-649.

22. Robertson A, Lundgren T, Andreasen JO, Dietz W, Hoyer I and Noren JG. Pulp calcifications in traumatized primary incisors. A morphological and inductive analysis study. Eur J Oral Sci 105(3): 196-206, 1997

23. Robertson A, Andreasen FM, Bergenholtz G, Andreasen JO and Noren JG. Incidence of pulp necrosis subsequent to pulp canal obliteration from trauma of permanent incisors. J Endod 22(10): 557-60, 1996 